\title{
Study of land surface temperature and spectral emissivity using multi-sensor satellite data
}

\author{
P K Srivastava ${ }^{1}$, T J Majumdar ${ }^{2, *}$ and Amit K Bhattacharya ${ }^{1}$ \\ ${ }^{1}$ Department of Geology $\&$ Geophysics, Indian Institute of Technology, Kharagpur 721 302, India. \\ ${ }^{2}$ Earth Sciences and Hydrology Division, Marine and Earth Sciences Group, Remote Sensing Applications Area, \\ Space Applications Centre (ISRO), Ahmedabad 380 015, India. \\ *e-mail: tjmajumdar@rediffmail.com
}

In this study, an attempt has been made to estimate land surface temperatures (LST) and spectral emissivities over a hard rock terrain using multi-sensor satellite data. The study area, of about $6000 \mathrm{~km}^{2}$, is a part of Singhbhum-Orissa craton situated in the eastern part of India. TIR data from ASTER, MODIS and Landsat ETM+ have been used in the present study. Telatemp Model AG-42D Portable Infrared Thermometer was used for ground measurements to validate the results derived from satellite (MODIS/ASTER) data. LSTs derived using Landsat ETM+ data of two different dates have been compared with the satellite data (ASTER and MODIS) of those two dates. Various techniques, viz., temperature and emissivity separation (TES) algorithm, gray body adjustment approach in TES algorithm, Split-Window algorithms and Single Channel algorithm along with NDVI based emissivity approach have been used. LSTs derived from bands 31 and 32 of MODIS data using Split-Window algorithms with higher viewing angle $\left(50^{\circ}\right)$ (LST1 and LST2) are found to have closer agreement with ground temperature measurements (ground LST) over waterbody, Dalma forest and Simlipal forest, than that derived from ASTER data (TES with AST 13). However, over agriculture land, there is some uncertainty and difference between the measured and the estimated LSTs for both validation dates for all the derived LSTs. LST obtained using Single Channel algorithm with NDVI based emissivity method in channel 13 of ASTER data has yielded closer agreement with ground measurements recorded over vegetation and mixed lands of low spectral contrast. LST results obtained with TIR band 6 of Landsat ETM+ using Single Channel algorithm show close agreement over Dalma forest, Simlipal forest and waterbody with LSTs obtained using MODIS and ASTER data for a different date. Comparison of LSTs shows good agreement with ground measurements in thermally homogeneous area. However, results in agriculture area with less homogeneity show difference of LST up to $2^{\circ} \mathrm{C}$. The results of the present study indicate that continuous monitoring of LST and emissivity can be undertaken with the aid of multi-sensor satellite data over a thermally homogeneous region.

\section{Introduction}

Land surface temperature (LST) and emissivity $(\varepsilon)$ are important parameters in energy budget estimation, land cover assessment and other earth surface characteristics related studies. LST, which is controlled by the surface energy balance, atmospheric state and thermal properties of the surface/subsurface rocks, is one of the important parameters in several environmental models (Becker and Li 1990). Emissivity $(\varepsilon)$ is also an important factor in the study of silicate rock (Lyon 1965; Vincent and Thomson 1972), which is a dominant constituent of surface/subsurface rocks. Thermal infrared (TIR) remote sensing is the only possible approach to retrieve LST and $\varepsilon$ over

Keywords. Land surface temperature; emissivity; Singhbhum-Orissa craton; temperature and emissivity separation; NDVI based emissivity. 
Table 1. Data acquisition details of various daytime imagery and ground measurements.

\begin{tabular}{cccccc}
\hline Year & $\begin{array}{c}\text { Date } \\
\text { (day/month) }\end{array}$ & $\begin{array}{c}\text { Ground } \\
\text { measurements } \\
\text { time (IST) }\end{array}$ & $\begin{array}{c}\text { Landsat } 7 \\
\text { time (IST) }\end{array}$ & $\begin{array}{c}\text { ASTER } \\
\text { time (IST) }\end{array}$ & $\begin{array}{c}\text { MODIS } \\
\text { time (IST) }\end{array}$ \\
\hline 2000 & $14 / 10$ & - & $10: 04$ & $10: 44$ & $10: 30$ \\
2001 & $26 / 10$ & - & $10: 00$ & $10: 29$ & $10: 30$ \\
2005 & $18 / 01$ & $10: 00-11: 00$ & - & - & - \\
& $19 / 01$ & $10: 00-11: 00$ & - & - & $10: 28$ \\
2007 & $20 / 01$ & $10: 00-11: 00$ & - & - & - \\
& $10 / 01$ & $10: 00-11: 00$ & - & - & - \\
& $11 / 01$ & $10: 00-11: 00$ & - & $10: 24$ & $10: 24$ \\
\hline
\end{tabular}

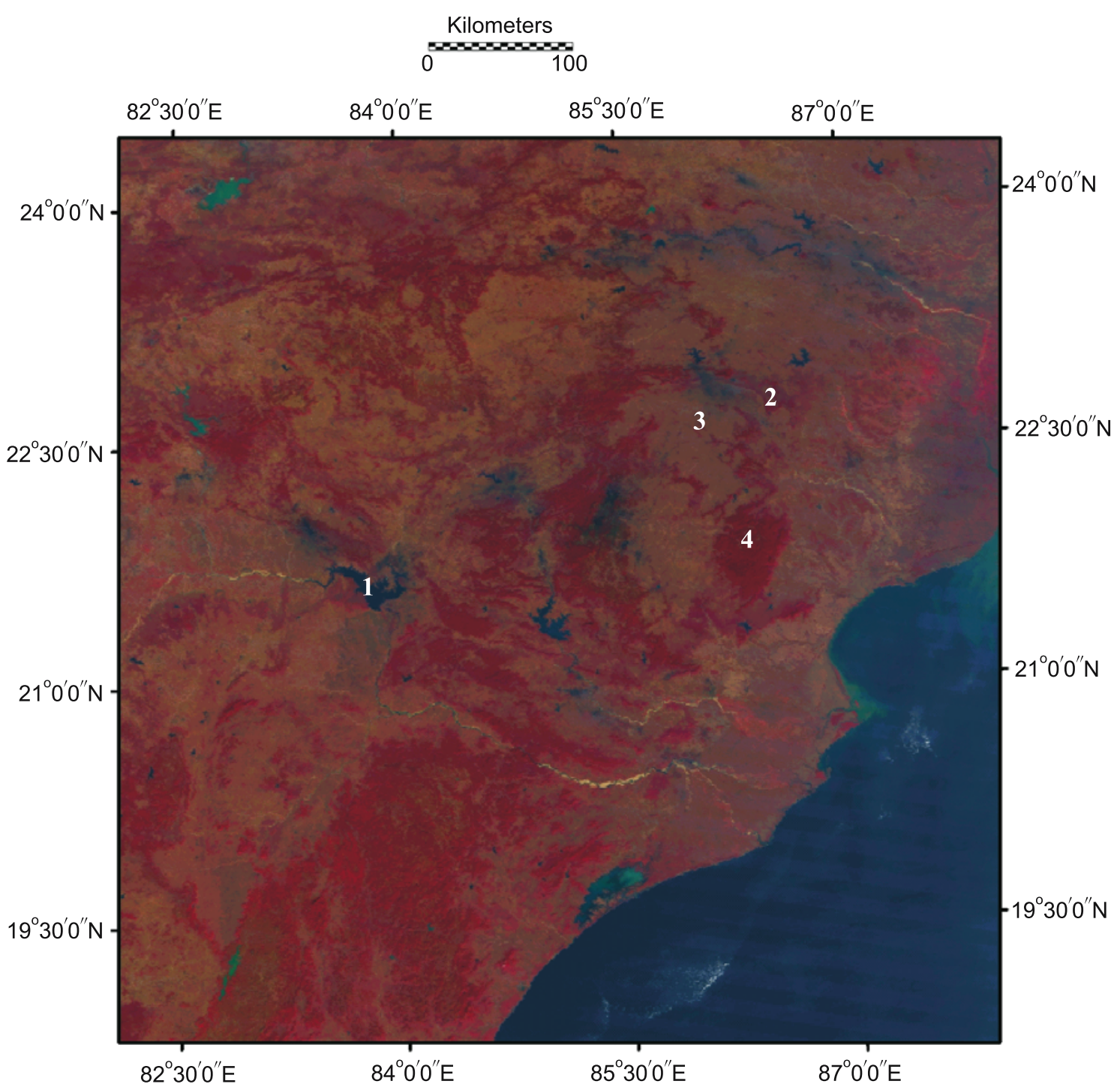

Figure 1. Location of the study area with selected field sites for surface temperature measurements from MODIS data. (1) Waterbody of Hirakud dam, (2) Dalma forest, (3) agriculture land, (4) Simlipal forest.

large portions of the earth surface. Emissivities are retrieved directly from satellite data. LST can be subsequently estimated from single band of the radiance data, once the atmospheric parameters and emissivities are known. Since surface temperatures are independent of wavelengths, LSTs derived 
from multi-sensor data at nearly identical time can be compared. On the other hand, it is difficult to compare the emissivity results derived from different sensors, as wavelengths are different for different sensors.

Many successful attempts have been made to derive emissivities; some are qualitative approaches which do not permit one to know either relative or absolute emissivity values (Soha and Schwartz 1978); while others are quantitative methods that permit one to know the relative or absolute emissivity values (Becker and $\mathrm{Li}$ 1990). Kahle et al (1980) assumed a constant value for emissivity in a band; while Watson (1992) considered that emissivity value does not change with time. Kealy and Hook (1993) proposed 'alpha derived relative emissivity' method. Goïta and Royer (1997) had estimated emissivity and temperature using TIR and SWIR (Short Wavelength Infrared) from AVHRR data; while Gillespie et al (1998) had proposed temperature and emissivity separation (TES) algorithm using TIR bands of ASTER (Advanced Spaceborne Thermal Emission and Reflection Radiometer) data. Emissivity of the land surface, obtained through land cover classification method (Snyder et al 1998) or NDVI method (Van de Griend and Owe 1993; Valor and Casselles 1996; Carlson and Riplay 1997; Sobrino and Raissoumi 2000), was used by researchers in Single Channel algorithm (Qin et al 2001) and Split-Window algorithm (Becker and Li 1990; Wan and Dozier 1996; Wan et al 2004) to estimate LST (Dash et al 2002). Barsi et al (2003) estimated LST from Landsat imagery using Single Channel algorithm. Sobrino et al (2003) used Split-Window algorithm to estimate LST from MODIS (Moderate Resolution Imaging Spectroradiometer) data. Jacob et al (2004) compared LST and emissivity values obtained using ASTER and MODIS data. Coll et al (2005) had compared LST estimated using AATSR and MODIS data. Jiménez-Muñoz et al (2006) used NDVI based emissivity method to obtain surface emissivities over agricultural areas from ASTER data, and found that band 13 gave most accurate emissivity measurement. Coll et al (2007) suggested improvement of TES algorithm, by considering known emissivity of gray body targets, using band 13 of ASTER. A multi-sensor approach could be used for LST monitoring on spatial scale using TIR data of ASTER, MODIS and Landsat 7.

In the present study, a multi-sensor approach was used to obtain LSTs over different land use/land covers in the study area, which were later validated with ground measurements carried out during the overpass time of satellite sensors (table 1).

\section{Study area}

The study area lies in the eastern part of India, between latitudes $19^{\circ}-24^{\circ} \mathrm{N}$ and longitudes $82^{\circ}-88^{\circ} \mathrm{E}$ (figure 1 ). It has tropical climate with average temperature varying from $15^{\circ} \mathrm{C}$ in the winter (December-February) to $40^{\circ} \mathrm{C}$ in the summer (March-May). The average annual rainfall in the area is around $1300 \mathrm{~mm}$. The soil of the area is sandy clay enriched in minerals; in terms of soil taxonomy, it is known as Alfisols. The study area is predominantly covered by forests (Simlipal and Dalma forest), agriculture land, and one large waterbody (Hirakud dam) and several scattered small waterbodies (figure 1). Simlipal forest, Dalma forest and Hirakud dam have large uninterrupted areal coverages of several square $\mathrm{km}$, while agriculture land is interrupted with shrubs, rice crops and plantation.

\section{Data used}

In the present study, ground temperature measurements were carried out over agriculture land, waterbodies, Simlipal forest and Dalma forest (figure 1) concurrently with satellites (table 1) overpass during January 18-20, 2005 and January 10-12, 2007 using Telatemp Model AG-42D Infrared Thermometer and contact thermometer for LST validation at various locations. Thermal homogeneity at measurement sites was assessed at both the ASTER and MODIS spatial scales and LST results were compared with ground measurements.

\subsection{Satellite data}

LST and emissivity were derived, using various algorithms, from the TIR bands of ASTER, MODIS and Landsat 7 ETM+ sensors. All the three satellite data were acquired on same dates, viz., 14 October 2000 and 26 October 2001, but at different times. Additionally, two satellite data, viz., ASTER and MODIS data were also acquired on 20 January 2005 and 12 January 2007 at the same time. Table 1 shows the details of satellite data acquisitions utilized in this study. ASTER and MODIS data products were obtained from EOS data Gateway (http://elpdl03.cr.usgs.gov/ pub/imswelcome/).

Georeferenced at-sensor radiance (ASTER L1B), surface emissivity (AST05), VNIR surface reflectance (AST07), surface kinetic temperature (AST08) and atmospheric compensated surface radiance (AST09) imagery, as well as MODIS data products (MOD11_L2) of different dates were acquired through EOS data gateway. 
Georeferenced MODIS level 1B data (bands 31 and 32) and Landsat ETM+ data were also used for LST retrieval.

\subsection{Ground measurements}

Surface temperature measurements were carried out at various measurement sites in the study area, viz., agriculture land, waterbodies, Simlipal forest and Dalma forest concurrently with satellite data, during January 18-20, 2005 and January 10-12, 2007 between 10:00 and 11:00 IST (table 1). A Single Channel portable AG-42D thermal infrared thermometer (range: $8-14 \mu \mathrm{m}$ ) was used for collecting ground surface temperatures with resolution of $0.1^{\circ} \mathrm{C}$. This instrument has temperature accuracy of $\pm 0.5^{\circ} \mathrm{C}$ with low noise of $<0.05^{\circ} \mathrm{C}$. It has an emissivity adjustment panel to calibrate the radiation characteristic of the surface body, being measured in the emissivity range 0.01-0.99 with a resolution of 0.01 . Surface temperatures measured using AG-42D was automatically corrected for emissivity effects by adjusting the emissivity control panel to the target land surface emissivity value (Salisbury and D'Aria 1992). AG-42D thermometer was calibrated against a reference blackbody before each field measurements, to adhere to instrument accuracy of $\pm 0.5^{\circ} \mathrm{C}$. In order to capture the spatial variability of the surface temperature within the measured site, several readings were recorded at intervals of about 100 meter around the site. These data were averaged and standard deviation was calculated for the estimation of spatial and temporal variability of LST over a part of the test site. Temporal/spatial analyses of the observed ground temperatures at different measurement sites for the entire study area show that standard deviation $(\sigma)$ varies between $\pm 0.51^{\circ} \mathrm{C}$ and $\pm 0.70^{\circ} \mathrm{C}$. The variability of LST over the entire measurement period was also considered in order to check the consistency of the ground data. Effect of canopy was also taken into account while collecting ground measurements data.

\section{Methodology}

In the present study, LSTs were retrieved from TIR bands of ASTER (bands 10-14), MODIS (bands 31 and 32) and Landsat ETM+ (band 6). Various LST and emissivity retrieval algorithms, viz., TES algorithms, NDVI based Single Channel algorithms, Split-Window algorithms were applied on multi-sensor data. Thermal homogeneity of measurement sites over agriculture land, waterbodies, Simlipal and Dalma forest areas were assessed at the ASTER spatial scales $\left(90 \times 90 \mathrm{~m}^{2}\right)$ for all the acquisition dates of ASTER data. For each measurement site, the LSTs for the pixels closest to each measurement site were extracted, by considering arrays of $3 \times 3,5 \times 5$ and $11 \times 11$ pixels centered around the selected target pixel, for calculating the average temperature $\left(T_{\mathrm{av}}\right)$, standard deviation $(\sigma)$, minimum $\left(T_{\min }\right)$ and maximum $\left(T_{\max }\right)$ temperatures. Low $\sigma$ value is indicative of least spatial variation of temperature and hence better thermally homogeneous site, while high $\sigma$ is for significant change of temperature and thus low homogeneity. The spatial scale of $11 \times 11$ pixels (equivalently, $1 \times 1 \mathrm{~km}^{2}$ ) was utilized to compare the result with MODIS LST of $1 \mathrm{~km}$ spatial resolution. Details of each algorithm applied on TIR data of different sensors are given below.

\subsection{Temperature and emissivity separation (TES) method}

Temperature and emissivity separation (TES) method (Gillespie et al 1998) has been used for deriving LST and emissivity estimations from five TIR bands $(10-14 \mu \mathrm{m})$ of ASTER data.

TES products of surface emissivity (AST05) and LST (AST08) were acquired for comparison with those obtained by other algorithms. Histogram plots of vegetation emissivities in bands 10, 11, 13 and 14 obtained through TES algorithm show that vegetation emissivity in TES algorithm is overestimated. This is due to the iterative process adopted in TES algorithm over low spectral contrast regions.

\subsection{Improvement of TES algorithm}

The accuracy of the TES algorithm derived LST and emissivity depends on the accurate determination of the minimum maximum difference (MMD) of emissivities. MMD threshold method in TES algorithm is very suitable for the identification of targets with low MMD $(<0.03)$, but it is unsuitable when the target emissivity value lies close to the threshold value of $\sim 0.03$. The problem related to the TES thresholding is referred to as 'scaling error', which corresponds to a jump in the scaling value, creating step discontinuities in the image whenever there is a transition from vegetation to soil. Coll et al (2007) had carried out detailed study over low spectral surfaces of rice crop and waterbody as well as over high spectral contrast surface of beach sand, in order to analyse the performance of TES algorithms. They observed largest difference in radiance (up to $3.0 \%$ ) in band 10 which leads to estimated change of $2.5^{\circ} \mathrm{C}$ in temperature or $7 \%$ in emissivity; and lowest difference of radiance (up to $0.5 \%$ ) in band 13 which has shown a change of estimated temperature 
of around $0.5^{\circ} \mathrm{C}$. Thus, band 10 is likely to add error up to $2.5^{\circ} \mathrm{C}$ in LST estimation. Band 13 is considered as the most suitable band for LST study due to its good performance in radiance measurement with actual field result. Gray body adjustment method (Tanooka et al 2005; Coll et al 2007; Hook et al 2007) was proposed to minimize the error in LST. For targets such as waterbody and vegetation, the surface temperature is calculated for band 13 using the known emissivity value. The surface temperature obtained from band 13 is assumed to be true and used to simulate the radiance at the ground level with known emissivities for other bands. Hook et al (2007) found strong linear relationship between ASTER DN and simulated at-ground radiance.

Gray body adjustment approach was applied in the present study; that is, initially adjusting the radiance in other bands, and then applying the TES method for LST and emissivity estimation in five bands. Regression analyses of at-sensor DN image with adjusted at-ground radiance were carried out at several places in the vegetated areas covering wide variation of temperature. A linear correlation was found with strong correlation coefficient $\left(r^{2}>0.94\right)$ in all the bands which has been used in converting at-sensor DN (ASTER L1B) to atmospherically corrected atground ASTER radiances. TES algorithm was applied on adjusted radiances to retrieve surface emissivities in five bands and subsequently used in the estimation of LST.

\subsection{NDVI method}

Jiménez-Muñoz et al (2006) retrieved surface emissivities following NDVI method on ASTER data using co-acquired ASTER VNIR bands over agriculture land, and compared the results with the emissivities retrieved through the TES method. The results of comparison show that differences are $<1 \%$ for ASTER band 13 and $<1.5 \%$ for band 14 , but $>2 \%$ for bands 10,11 and 12 . In-situ emissivity measurements indicate that the observed differences in the results in bands 13 and 14 are within those anticipated; but the larger differences for bands 10-12 suggest the presence of problems related to atmospheric compensation and model assumption. Problem in the application of TES algorithm arises due to different scaling of high-and-low MMD emissivity spectra. NDVI method uses co-acquired VNIR bands of ASTER for emissivity estimation in TIR bands. These emissivity values were used in Single Channel algorithm for LST retrieval.

Spectral emissivities in all five bands of ASTER were estimated and compared with ASTER library of 58 soil emissivity spectra, which includes 9
Alfisols samples occurring in the study area. The mean values for the soil samples show high standard deviations $(>0.03)$ in the spectral range of $8-9.5 \mu \mathrm{m}$ (ASTER bands 10, 11, 12), and low standard deviations $(<0.03)$ in spectral range of 10-12 $\mu \mathrm{m}$ (ASTER bands 13, 14 and Landsat 7 band 6). It is expected that average emissivity of Alfisols in Landsat 7 and ASTER bands 13, 14 will provide good results while ASTER bands 10-12 will give poor results.

\subsection{Split-Window algorithm}

The Split-Window algorithm has been used by many researchers for LST retrieval (Becker and Li 1990; Wan and Dozier 1996; Majumdar and Mohanty 1998; Sobrino et al 2001; Coll et al 2005). This method does not need profiles of atmospheric water vapour and temperature. It corrects for atmospheric effects based on the differential absorption in adjacent thermal infrared bands rather than on absolute atmospheric transmission in a single band; and hence, it is less sensitive to the optical properties of the atmosphere. In the present study, two models, namely, (i) a viewing angle dependent generalized Split-Window algorithm (LST1) developed by Wan and Dozier (1996); and (ii) a quadratic emissivity dependent algorithm have been considered for LST estimation using MODIS bands 31 and 32. Split-Window algorithm (LST2) for LST (Sobrino et al 2003; Coll et al 2005) retrieval from MODIS data of both dates, viz., January 20, 2005 and January 12, 2007, was utilized. NDVI threshold method (Sobrino et al 2001) has been considered in this study to estimate surface emissivity for MODIS data.

\section{Results and discussion}

Results of all LST values, both ground measured as well as those derived from different satellite data, along with the corresponding standard deviations $(\sigma)$ have been presented in table 2. Field measurements of ground surface temperatures were carried out in agriculture land, waterbody of Hirakud dam, Dalma forest and Simlipal forest (figure 1) concurrently with satellites' overpasses (table 1) using Telatemp Model AG-42D Infrared Thermometer in the study area. Ground temperatures were compared with standard ASTER LST product (AST08) derived through TES algorithm, NDVI method based Single Channel algorithm for ASTER LST (AST13) and LST results (LST1 and LST2) using Split-Window algorithms on MODIS data. LST derived from bands 31 and 32 of MODIS data using Split-Window algorithms (LST 1 and LST 2) are found to have good agreement with 
Table 2. Land surface temperature (LST) along with uncertainty $(\sigma)$ in degree Celsius over different measurement sites for given dates using various algorithms.

\begin{tabular}{|c|c|c|c|c|c|c|c|}
\hline $\begin{array}{l}\text { Date (day/ } \\
\text { month/year) }\end{array}$ & $\begin{array}{l}\text { Location } \\
\text { sites }\end{array}$ & $\begin{array}{c}\text { TES } \\
(\mathrm{LST} \pm \sigma)\end{array}$ & $\begin{array}{c}\mathrm{AST} 13 \\
(\mathrm{LST} \pm \sigma)\end{array}$ & $\begin{array}{c}\mathrm{LST} 1 \\
(\mathrm{LST} \pm \sigma)\end{array}$ & $\begin{array}{c}\mathrm{LST} 2 \\
(\mathrm{LST} \pm \sigma)\end{array}$ & $\begin{array}{c}\mathrm{L} 7 \\
(\mathrm{LST} \pm \sigma)\end{array}$ & $\begin{array}{c}\text { Ground } \\
(\mathrm{LST} \pm \sigma)\end{array}$ \\
\hline \multirow[t]{4}{*}{$12 / 01 / 2007$} & WB & $22.48 \pm 0.53$ & $21.41 \pm 0.28$ & $22.38 \pm 0.26$ & $22.78 \pm 0.36$ & - & $22.20 \pm 0.51$ \\
\hline & $\mathrm{DF}$ & $20.87 \pm 0.45$ & $21.40 \pm 0.53$ & $21.61 \pm 0.48$ & $22.05 \pm 0.53$ & - & $22.30 \pm 0.62$ \\
\hline & $\mathrm{AL}$ & $28.07 \pm 1.66$ & $28.82 \pm 1.34$ & $29.08 \pm 0.62$ & $28.70 \pm 0.75$ & - & $30.40 \pm 0.70$ \\
\hline & $\mathrm{SF}$ & $21.28 \pm 0.54$ & $20.40 \pm 0.46$ & $19.16 \pm 0.48$ & $19.62 \pm 0.49$ & - & $20.30 \pm 0.55$ \\
\hline \multirow[t]{4}{*}{$20 / 01 / 2005$} & WB & $22.69 \pm 0.53$ & $21.62 \pm 0.28$ & $22.59 \pm 0.26$ & $22.99 \pm 0.36$ & - & $22.30 \pm 0.51$ \\
\hline & $\mathrm{DF}$ & $21.21 \pm 0.55$ & $20.69 \pm 0.53$ & $22.35 \pm 0.52$ & $22.51 \pm 0.48$ & - & $22.50 \pm 0.57$ \\
\hline & $\mathrm{AL}$ & $29.08 \pm 1.90$ & $28.89 \pm 1.82$ & $29.17 \pm 0.53$ & $28.72 \pm 0.49$ & - & $31.10 \pm 0.70$ \\
\hline & $\mathrm{SF}$ & $21.31 \pm 0.57$ & $20.85 \pm 0.50$ & $18.38 \pm 0.34$ & $18.75 \pm 0.35$ & - & $21.30 \pm 0.58$ \\
\hline \multirow[t]{3}{*}{$26 / 10 / 2001$} & WB & $28.71 \pm 0.05$ & - & $27.60 \pm 0.18$ & - & $29.58 \pm 0.35$ & - \\
\hline & $\mathrm{DF}$ & $28.29 \pm 0.34$ & - & $27.96 \pm 0.20$ & - & $29.27 \pm 0.74$ & - \\
\hline & $\mathrm{AL}$ & $31.72 \pm 0.61$ & - & $33.16 \pm 0.70$ & - & $35.03 \pm 1.01$ & - \\
\hline \multirow[t]{3}{*}{$14 / 10 / 2000$} & WB & $29.17 \pm 0.43$ & - & $28.75 \pm 0.19$ & - & $27.38 \pm 0.40$ & - \\
\hline & $\mathrm{DF}$ & $27.49 \pm 0.40$ & - & $27.23 \pm 0.32$ & - & $26.7 \pm 0.51$ & - \\
\hline & $\mathrm{AL}$ & $32.17 \pm 0.63$ & - & $33.52 \pm 0.67$ & - & $34.60 \pm 1.08$ & - \\
\hline
\end{tabular}

WB: Waterbody; DF: Dalma forest; AL: agriculture land; SF: Simlipal forest; TES (Temperature \& Emissivity Separation); AST13 (NDVI based Single Channel algorithms on ASTER); LST1 (Wan's Split-Window algorithm); LST2 (Sobrino's Split-Window algorithms); L 7(NDVI based Single Channel algorithms on Landsat 7); Ground (ground surface temperature measurements).

ground temperature measurements (ground LST) over waterbody, Dalma forest and Simlipal forest; while in agriculture land, there is high uncertainty and difference in measured and estimated LST for both validation dates (figures 2 and 3 , and table 2). Results of thermal homogeneity study show that the thermal homogeneity of all the sites except the agriculture land is quite good at ASTER scale $(\sigma<0.57)$ and at MODIS scale $(\sigma<0.35)$.

\subsection{Comparison of LSTs derived from ASTER and MODIS data with ground measurements}

LSTs were retrieved from TIR sensors of ASTER (bands 10-14) and MODIS (bands 31, 32) using various algorithms and compared with ground temperature measurements (table 2) for January 20, 2005 and January 12, 2007 (figure 2 and table 2). LST derived from bands 31 and 32 of MODIS data using Split-Window algorithms (LST1 and LST2) are found to have closer agreement with ground temperature measurements (ground LST) over waterbody, Dalma forest and Simlipal forest than that derived from ASTER data (TES with AST 13). However, over agriculture land, there is some uncertainty and difference between the measured and estimated LSTs on both the validation dates. Thus, it can be suggested that MODIS data product can be alternatively chosen for study, in case of non-availability of ASTER
L1B data. Uncertainty $(\sigma)$ observed over measurement site in different TIR sensors are indicative of spatial variability of LST within a measurement site. A large $\sigma$ value observed over agriculture land indicates that agriculture land radiance is mixed with other land use classes and hence not suitable for LST comparison with ground measurements. Low $\sigma$ values observed over Dalma forest, Simlipal forest and waterbody are indicative of thermal homogeneity. Hence, these sites are suitable for LST comparison with ground measurements. The uncertainty in ground measurements can be explained as due to instrument accuracy $\left( \pm 0.50^{\circ} \mathrm{C}\right)$ and spatial/temporal changes (up to $\pm 0.50^{\circ} \mathrm{C}$ ) during field observation. Considering the uncertainty in ground LST measurements over Dalma forest, Simlipal forest and waterbody, LST derived from TIR sensors are within $\pm 2^{\circ} \mathrm{C}$ with the ground LST.

\subsection{Comparison of LSTs derived from ASTER, Landsat 7 and MODIS data products}

MODIS LST data products (MOD11_L2) of January 20, 2005 and January 12, 2007 were compared with LST results obtained from MODIS L1B data, which were subsequently validated with ground LST measurements (figure 2). Results show that MODIS data products have good agreement, so it can be taken for comparison with LST results from other TIR sensors. LSTs were retrieved from TIR sensors of ASTER (bands 10-14), Landsat 7 


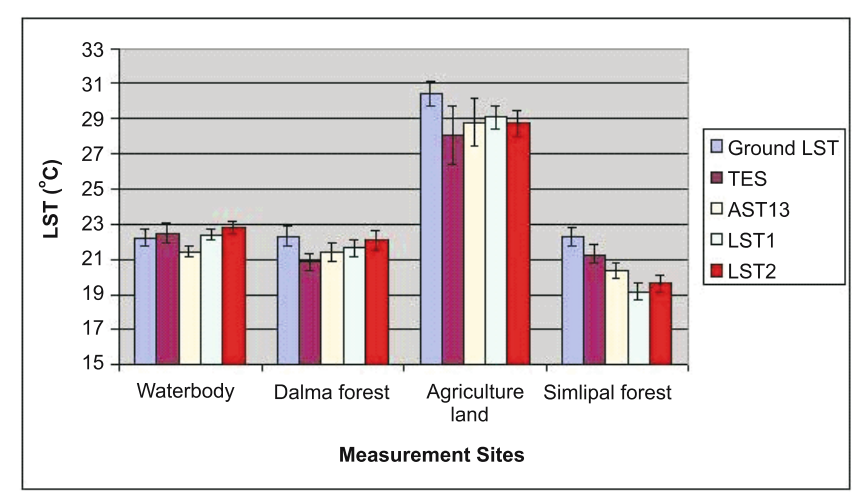

Figure 2. Comparison of LSTs from ASTER and MODIS data of January 12, 2007 with Ground LST. TES (Temperature \& Emissivity Separation) of ASTER; AST13 (NDVI based Single Channel algorithms on ASTER); LST1 (Wan's Split-Window algorithm on MODIS); LST2 (Sobrino's Split-Window algorithms on MODIS); Ground (Ground surface temperature measurements). Error bars indicate uncertainty in measurements.

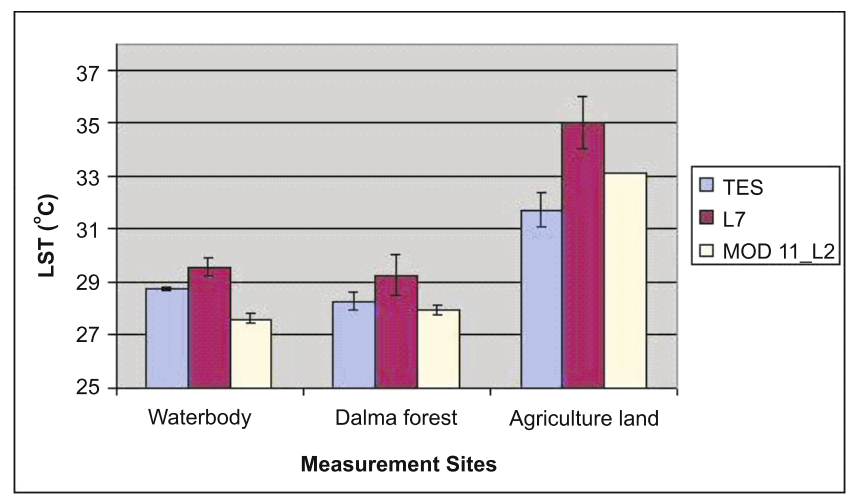

Figure 3. Comparison of LSTs from ASTER, Landsat 7 and MODIS data of October 26, 2001. TES (Temperature \& Emissivity Separation) of ASTER; L 7 (NDVI based Single Channel algorithms on Landsat 7); MOD11_L2 (standard MODIS data product). Error bars indicate uncertainty in measurements.

(band 6) and MODIS (bands 31, 32) using various algorithms (table 2) for October 26, 2001 and October 14, 2000 (figure 3 and table 2). Comparison of LSTs derived from Landsat 7 (L 7), ASTER (TES) and MODIS data product (MOD11_L2) shows close agreement over Dalma forest, Simlipal forest and waterbody for both the dates. However, agriculture land shows a difference of up to $2^{\circ} \mathrm{C}$ and high uncertainty $(\sigma)$. This is due to mixing of agriculture spectral radiance with other classes present near measurement site on spatial scales.

\section{Conclusions}

This study was carried out with the primary objective of finding the suitability of satellite data in providing land surface temperatures as well as land emissivities. Different algorithms were applied on TIR data of ASTER and MODIS and Landsat satellites in order to obtain surface emissivities and subsequent estimation of land surface temperatures (LSTs) over different land use classes in parts of Singhbhum-Orissa craton in eastern India. Field measurements of temperatures were carried out during the overpasses of these satellites in the study area, in order to validate LST results obtained using data from various TIR sensors. Results show that LST results obtained from TIR sensors over vegetation (Dalma forest and Simlipal forest) and waterbody (Hirakud dam) have good agreement with ground LST, but differs from that over agriculture land. The discrepancy between the derived LSTs and ground measured temperatures over agriculture land is due to lack of thermal homogeneity. Comparison of LSTs derived from multi-sensor TIR data with ground measurements shows that LSTs can be estimated within an accuracy of $\pm 2^{\circ} \mathrm{C}$ on different spatial resolutions. Thus, it can be concluded from this study that a multi-sensor approach can be applied for frequent monitoring of LST and emissivity over thermally homogeneous land surfaces on spatial scales.

\section{Acknowledgement}

The authors thank NASA for providing ASTER data.

\section{References}

Barsi J A, Schott J R, Palluconi F D, Helder D L, Hook S J, Markham B L, Chander R G and O'donnell E M 2003 Landsat TM and ETM+ thermal band calibration; Can. J. Rem. Sens. 28 141-153.

Becker F and Li Z-L 1990 Temperature independent spectral indices in thermal infrared bands; Rem. Sens. Environ. 32 17-33.

Carlson T N and Ripley D A 1997 On the relation between NDVI, fractional vegetation cover, and leaf area index; Rem. Sens. Environ. 62 241-252.

Coll C, Caselles V and Galve J M 2005 Ground measurements for the validation of land surface temperatures derived from AATSR and MODIS data; Rem. Sens. Environ. 97 288-300.

Coll C, Caselles V, Valor E, Niclòs R, Sánchez J M, Galve J M and Maria M 2007 Temperature and emissivity separation from ASTER data for low spectral contrast surfaces; Rem. Sens. Environ. 110 162-175.

Dash P, Göttsche F-M, Olesen F-S and Fischer H 2002 Land surface temperature and emissivity estimation from passive sensor data: Theory and practice - current trends; Int. J. Rem. Sens. 23 2563-2594.

Gillespie A, Rokugawa S, Matsuna G T, Cothern J S, Hook S and Kahle A B 1998 A temperature and emissivity separation algorithm for Advanced Spaceborne Thermal Emission and Reflection Radiometer (ASTER) images; IEEE Trans. Geosci. E Rem. Sens. 36 $1113-1126$. 
Goïta K and Royer A 1997 Surface temperature and emissivity separability over land surface from combined TIR and SWIR AVHRR data; IEEE Trans. Geosci. E Rem. Sens. 35 718-733.

Hook S J, Vaughan R G, Tonooka H and Schladow S G 2007 Absolute radiometric in-flight validation of Mid and Thermal Infrared data from ASTER and MODIS using the Lake Tahoe CA/NV, USA automated validation site; IEEE Trans. Geosci. \& Rem. Sens. 45 1798-1807.

Jacob F, Petitcolin F, Schmugge T, Vermote E, French A and Ogawa K 2004 Comparison of land surface emissivity and radiometric temperature derived from MODIS and ASTER sensors; Rem. Sens. Environ. 90 137-152.

Jiménez-Muñoz J C, Sobrino J A, Gillespie A, Sabol D and Gustafson W T 2006 Improved land surface emissivities over agricultural areas using ASTER NDVI; Rem. Sens. Environ. 103 474-487.

Kahle A B, Madura D P and Soha J M 1980 Middle infrared multispectral aircraft scanner data: Analysis for geological applications; App. Optics 19 2279-2290.

Kealy P S and Hook S 1993 Separating temperature and emissivity in thermal infrared multispectral scanner data: Implication for recovering land surface temperatures; IEEE Trans. Geosci. \& Rem. Sens. 31 1155-1164.

Lyon R J P 1965 Analysis of rocks by spectral infrared emission (8 to 25 microns); Econom. Geol. 60 715-736.

Majumdar T J and Mohanty K K 1998 Derivation of land surface temperatures from MOS-1 VTIR data using SplitWindow channel computation technique; Int. J. Rem. Sens. 19 287-294.

Qin Z, Karnieli A and Berliner P 2001 A mono-window algorithm for retrieving land surface temperature from Landsat TM data and its application to the Israel-Egypt border region; Int. J. Rem. Sens. 28 3719-3746.

Salisbury J W and D'Aria D M 1992 Emissivity of terrestrial materials in the $8-14 \mu \mathrm{m}$ atmospheric window; Rem. Sens. Environ. 42 83-106.
Snyder W C, Wan Z, Zhang Y and Feng Y-Z 1998 Classification-based emissivity for land surface temperature measurement from space; Int. J. Rem. Sens. 19 $2753-2774$.

Sobrino J A and Raissouni N 2000 Toward remote sensing methods for land cover dynamic monitoring: Application to Morocco; Int. J. Rem. Sens. 21 353-366.

Sobrino J A, Raissouni N and Li Z 2001 A comparative study of land surface emissivity retrieval from NOAA data; Rem. Sens. Environ. 75 256-266.

Sobrino J A, El Kharraz J and Li Z-L 2003 Surface temperature and water vapour retrieval from MODIS data; Int. J. Rem. Sens. 24 5161-5182.

Soha J M and Schwartz A A 1978 Multispectral histogram normalization contrast enhancement; Proc. 5th Canadian Symp. on Remote Sensing, Victoria, British Columbia, Canada, pp. 86-93.

Tanooka H, Palluconi F D, Hook S J and Matsunaga T 2005 Vicarious calibration of ASTER thermal infrared bands; IEEE Trans. Geosci. ES Rem. Sens. 43 2733-2746.

Valor E and Caselles V 1996 Mapping land surface emissivity from NDVI: Application to European, African and South American areas; Rem. Sens. Environ. 57 167-184.

Van de Griend A A and Owe M 1993 On the relationship between thermal emissivity and the normalized difference vegetation index for natural surfaces; Int. J. Rem. Sens. 14 1119-1131.

Vincent R and Thomson F 1972 Spectral compositional imaging of silicates rocks; J. Geophys. Res. 77 2465-2472.

Wan Z and Dozier J 1996 A generalized Split-Window algorithm for retrieving land surface temperature from space; IEEE Trans. Geosci. \& Rem. Sens. 34 892-905.

Wan Z, Zhang Y, Zhang Q and Li Z L 2004 Quality assessment and validation of the MODIS global land surface temperature; Int. J. Rem. Sens. 25 261-274.

Watson K 1992 Two-temperature method for measuring emissivity; Rem. Sens. Environ. 42 117-121. 